Diyala Journal of Engineering Sciences

Journal homepage: https://en.enginmag.uodiyala.edu.iq/

ISSN: 1999-8716 (Print); 2616-6909 (Online)

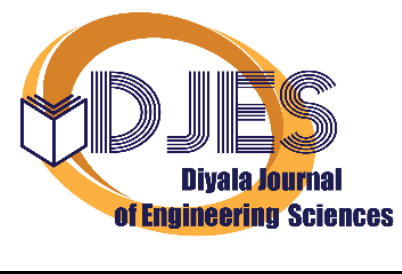

\title{
Reducing Effect of Vibration on Footing using Different Materials
}

\author{
Ali H. Hussein ${ }^{*}$, Waad A. Zakaria \\ Department of Chemical Engineering, College of Engineering, Daiyla University, Baquba City 32001, Iraq
}

\section{ARTICLE INFO}

Article history:

Received 5 May 2020

Accepted 28 June 2020

Keywords:

Trench; Materials; Isolated; Vibration

\section{ABSTRACT}

This paper investigates the reduction of vibration effect between two footings by placing a trench between them. On the first footing (designated as the source footing), on electric-rotary motor is fitted, it has dimensions of $(80 \times 80) \mathrm{mm}$. Beside the source footing a second footing is placed and on this footing the reduction in vibration effects are to be investigated. Both the source footing, nearby footing and trench are placed over compacted gypseous soil in a steel tank having gypsum content with $(50 \%)$. Tests are performed under dry and soaking conditions. The tests are managed under dynamic load for three frequencies $(8,14$ and 20$) \mathrm{Hz}$, to install amplitude, velocity, and acceleration of the footing before and after drilling the trench, also to compare between the materials to choose the best material to reduce vibrations. The results showed that all parameters in above for the footing varying in values when change the material used to filling trench.

\section{Introduction}

Israa (2017) explained the presence of gypseous soils is one of the effected problems that the civil engineer faces it in construction of buildings is, the gypseous is dissolved when its water content increases.

Safa (2011) showed the problem appeared after wetted by water from rainfall or from the raising of water table level from any source through constructing heavy buildings or hydraulic structures on these soils. the presence of gypseous soils is one of the effected problems that the civil engineer faces it in construction of buildings is, the gypseous is dissolved when its water content increases.

Prakash (1981) showed that the dynamic loads are generated from several sources like earthquakes, bomb explosions, machine operation with hammers, hammers and construction process such as piles driving, quarries, fast traffic including aircraft landing, winding loads due to water waves and other dynamic loads affecting foundations and soil structures.

Dudley (1970), Clemence and Finbarr (1981) showed that the gypsous soil can carry a huge load with a little magnitude of settlement, at natural state, but the problem begins when rising of water content which leads to considerable decreasing in volume.

Das (1990) explained the weathering process produces soils with a large range of particle-size distribution. So that many collapsible soils may be that they are products of weathering of origin rocks. Soluble and colloidal materials are leached out by weathering, resulting in large void ratios and thus unstable structures.

Woods (1968) explained that many of these vibrations effect on sensitive instruments functions, damage constructions and disturbs

*Corresponding author.

E-mail address: alihadihussein25 @ gmail.com

DOI: $10.24237 /$ djes.2020.13403 
citizens. Among isolation techniques applied to mitigate are active wave barriers and passive ones.

S. Ahmad and Al-Hussaini, (1991) showed, it had been using rectangular wave barriers represented in open or filled trenches (wave barriers) used to reduce ground vibrations caused by relatively small wave length Rayleigh wavelengths in homogeneous soil sediments by used conducting large-scale numerical investigation about the effect various geometric and physical parameters on the effectiveness of vibration screening of barriers. An advanced method for advanced boundary boundaries (BEM) includes high-level isoperimetric elements and sophisticated selfadaptive. He made study about the effect about of the dimensions of the depth, thickness and length of the trench, as well as the distance between the receiver and the cause of the vibration, in the case of the open trench and obtained a small value of amplitude, It was obtained for open trenches, the normal depth D is the management factor and the measured width $\mathrm{W}$ is unimportant, except for shallow depths $(\mathrm{D}<0.8)$.

Massarsch (2004) explained that which it can be used different methods to reduce traffic-induced vibrations are discussed. Special assertiveness is placed on rail-bound highest isolation effect. The gas cushion can resist the later earth pressure and such a flexible barrier has a vibration isolation effect which is comparable to an open trench this method offers makes it possible to create a flexible barrier to great depths, which has a very low impedance, that mean low density and low wave velocity.

\section{Definition of problem}

Spaced square footing placed from the source of vibration and between of them trench filled with type of materials on gypseous soil dry and soaked state as shown in Figure1. The footing was placed with intensity of loads is $21 \mathrm{~kg}$ in mass. The objective is to determine reduce of vibration effect in footing (amplitude, velocity, acceleration) and choose the best materials use to filled the trench, see Figure 1.

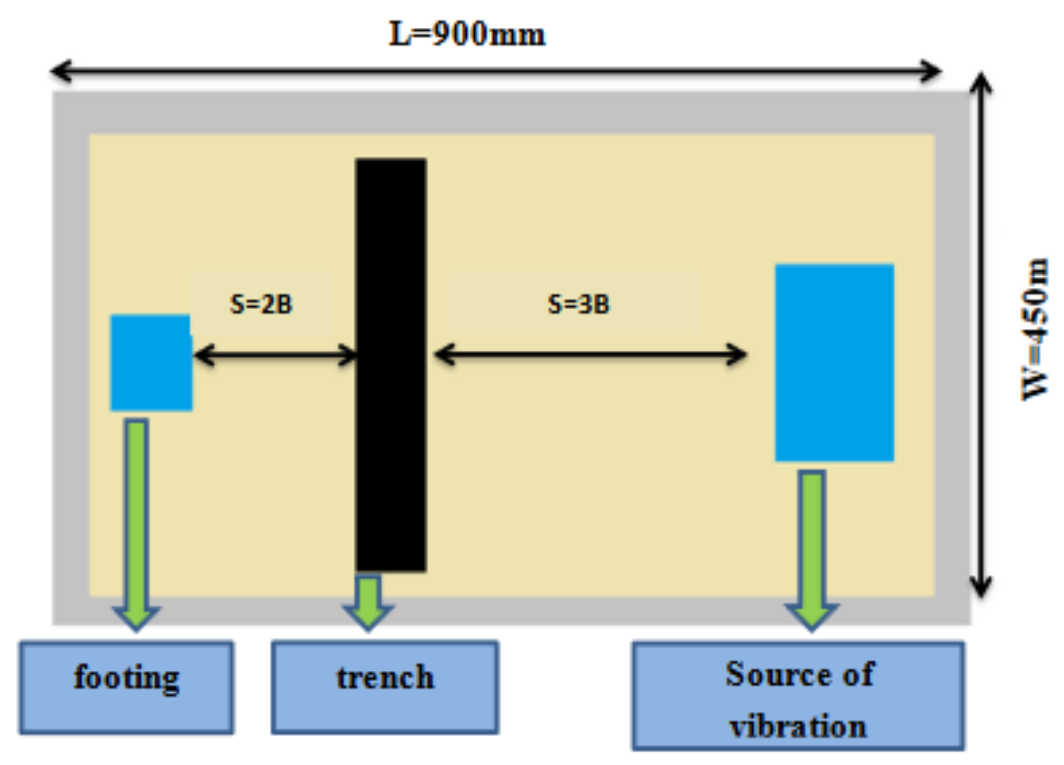

Fig 1. Layout of experimental model

\section{Preparation and test procedure}

The soil was taken from Tikrit Governorate located north of Iraq; it has been carried out for the testing program. Table 1 shows the physical properties of the soil. The sample of gypsums soil of gypseous content of (50\%) are classified as moderately severe (ASTM D5533-2003).

The gypseous soil is place in the steel container in three layers with a uniform field density using the hummer device. 
Table 1 Results of physical properties of sample

\begin{tabular}{|l|c|}
\hline \multicolumn{1}{|c|}{ Properties } & Value \\
\hline Specific Gravity (Gs) & 2.43 \\
\hline Liquid limit (L.L)\% & 20 \\
\hline Plastic limit (P.L)\% & N.P \\
\hline Plasticity Index (P.I) & N.P \\
\hline Compaction characteristics: Max. Dry unit weight(kN/m3) Optimum & 16.83 \\
Moisture content (\%) & 16.77 \\
\hline Passing sieve No. 200 (\%) & 18 \\
\hline Soil classification according to USCS system & SM \\
\hline Water content \% & 2.6 \\
\hline Uniformity coefficient Cu & 5.2 \\
\hline Coefficient of gradation Cc & 1.11 \\
\hline
\end{tabular}

\section{Materials used to fill trench}

\subsection{SBR rubber}

Rubber has been used recently in a group of applications, including as a lightweight filling material (Bosscheret al.,1997; Zornberget al., 2004; Humphrey, 2007) to isolate the vibrations in foundations (Tsang, 2008; Senetakiset al.,2009). In this study, rubber of is used to fill the trench. It was cut into small pieces, compared to the width of the footing with dimensions (0.015B-0.15B) mm and thickness approximately (1) $\mathrm{mm}$, see Figure 2.

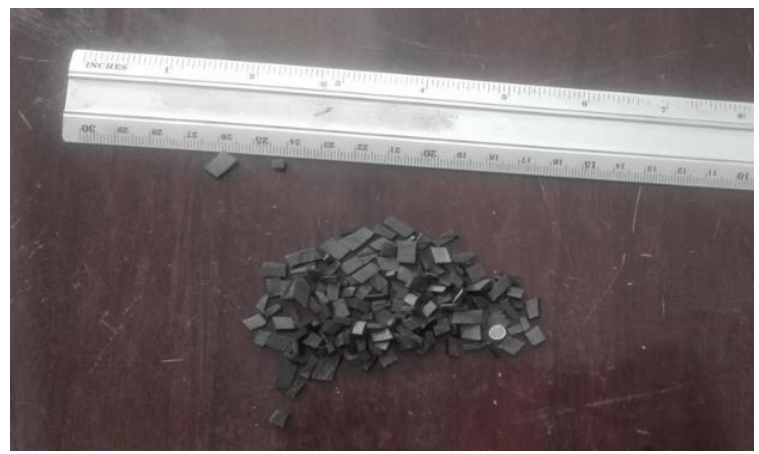

Fig 2. Pieces of rubber

\subsection{Styropor or Rigid Foam (XPS)}

The basic material is expanded Polystyrene foam, produced by the German firm B.A.S.F. and exported to the world under the name of Styropor (B. Sayil and E. GÜrdal,1999). Extruded Polystyrene (XPS) Insulation is moisture resistant rigid foam sheet well suited to meet the needs for a wide assortment of building applications. Its unit weight puts it in a separate category compared to other types of engineering lightweight materials.

\subsection{Low Density Polyethylene (LDPE)}

One of a family of polymers referred to collectively as a polyolefin, which are the most generally industrially produced plastics These polymers comprise $\mathrm{C}$ and $\mathrm{H}$ atoms and are distinguished by their low density (will float on water). The various types of polyethylene are classified according to their density. polyethylene with a density of between 0.91 to $0.94 \mathrm{~g} / \mathrm{cm}^{3}$, low-density polyethylene according the global market for see Figure 3.

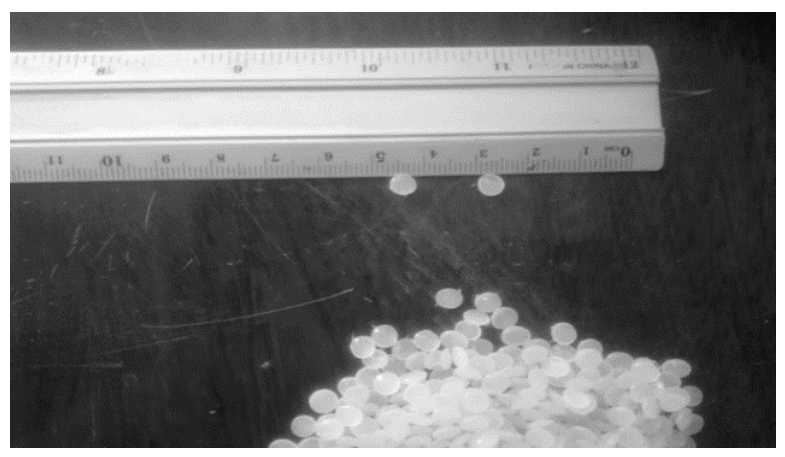

Fig 3. Low Density Polyethylene granules (LDPE)

\section{Results and discussion}

\subsection{Results of displacement amplitude \\ 5.1.1Amplitude for rubber}

Figure 4 the relationship between the amplitude with time in ordinary scale for frequency, namely, $8 \mathrm{~Hz}$ for dimensions of trench $($ length $=3 \mathrm{~B}$, depth $=\mathrm{B}$, thickness $=0.5 \mathrm{~B}$ ) at dry state. The measured amplitude for both treated and untreated seems to be almost constant. The advantage obtained in term of peak to peak point is about $70 \%$.

The same relation is drawn in Figure 5 but for soaked state. Here the treated curve has reduction in all aspects and improvement obtained here is $94 \%$ also calculated peak to peak in both Figures 4, 5 no noticeable fluctuation is seeming. 


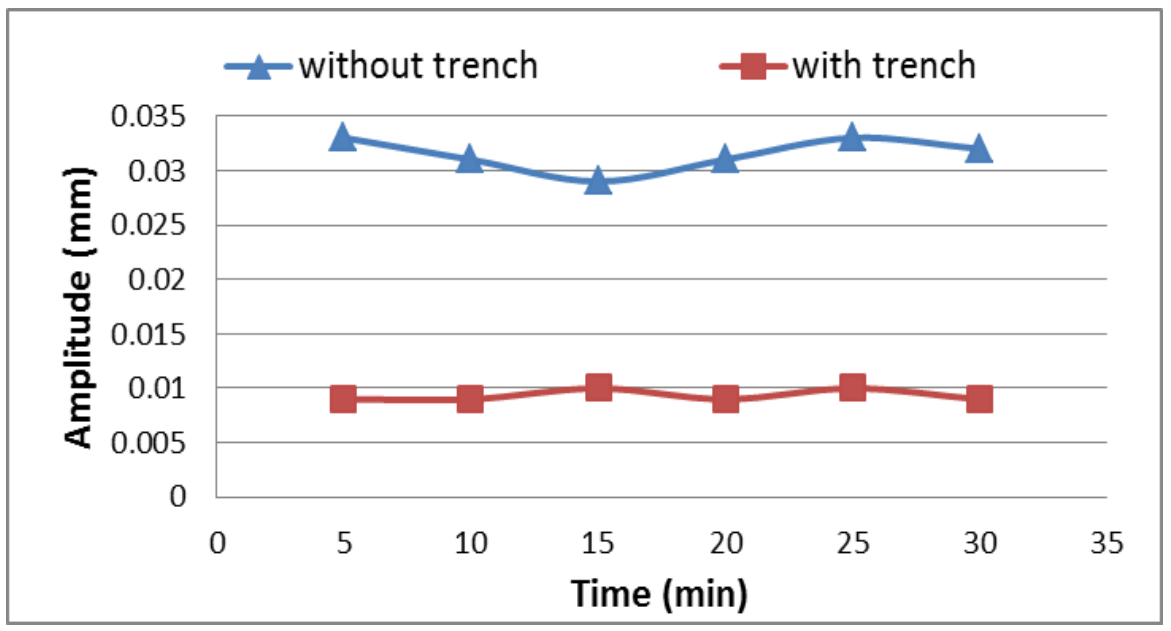

Fig 4. Variation of amplitude with time at frequency $(8 \mathrm{~Hz})$ for (length $=3 \mathrm{~B}$, depth $=\mathrm{B}$, thickness $=0.5 \mathrm{~B}$ ) at dry state to rubber

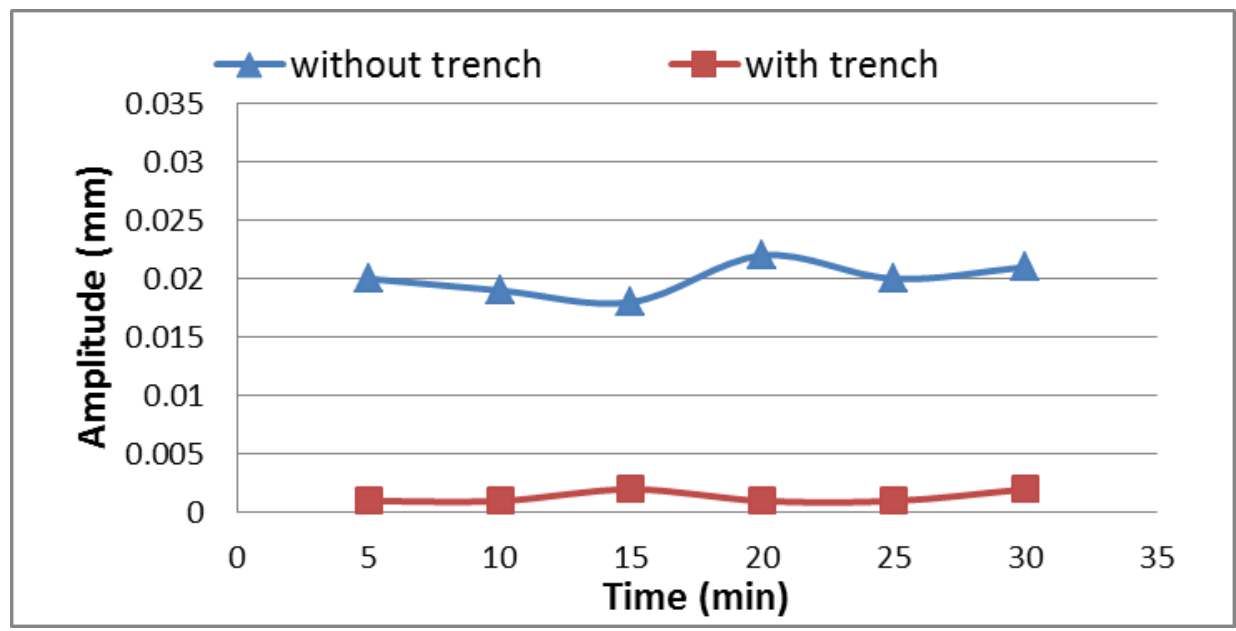

Fig 5. Variation of amplitude with time at frequency $(8 \mathrm{~Hz})$ for $($ length $=3 \mathrm{~B}$, depth $=\mathrm{B}$, thickness $=0.5 \mathrm{~B})$ at soaked state to rubber

\subsubsection{Amplitude for styropor or rigid foam} (XPS)

Figure 6 the relationship between the amplitude with time for frequency, namely, 8 $\mathrm{Hz}$ for dimensions (length $=3 \mathrm{~B}$, depth=B, thickness $=0.5 \mathrm{~B}$ ) at dry state. From the figure 6 it can be compared a vibration decrease tendency behind isolation trench, when placing the styropor trench, it can be seen both curves for treated and untreated have similar trend of behavior in fluctuations, and it is continuing to end of test. and effect of the styropor to reduce the vibration is $(67 \%)$ for peak to peak amplitude.

In Figure 7 shows immediately behind the barrier when the trench was filled with styropor in the same relationship but in soaked state. From the figure 6 it can be seen the curve of treated is start decrease until minute (10) then increase until minute (30), so it has a stable (almost) peak-to-peak improvement. It is $67 \%$ and calculated from Figure 6. 


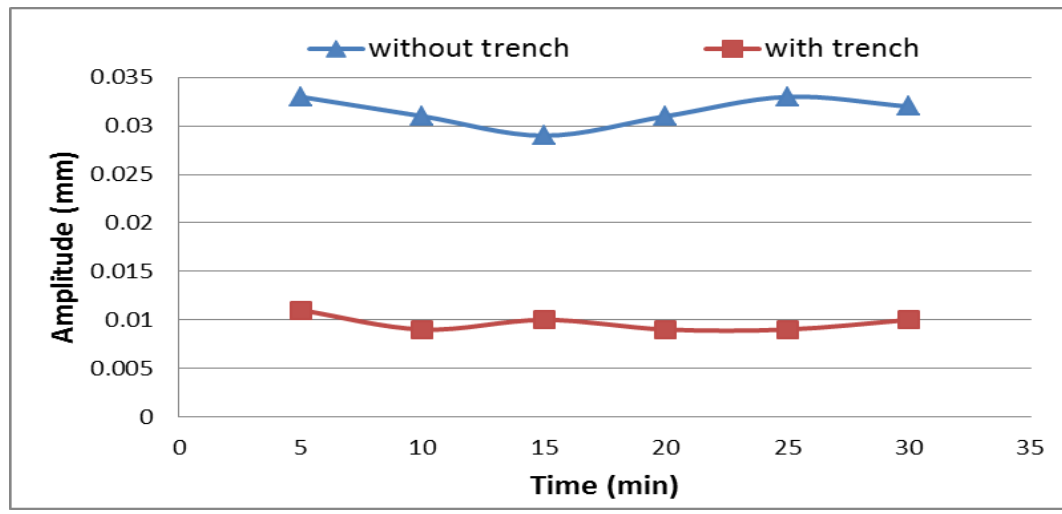

Fig 6. Variation of amplitude with time at frequency $(8 \mathrm{~Hz})$ for $($ length $=3 \mathrm{~B}$, depth $=\mathrm{B}$, thickness $=0.5 \mathrm{~B})$ at dry state styropor

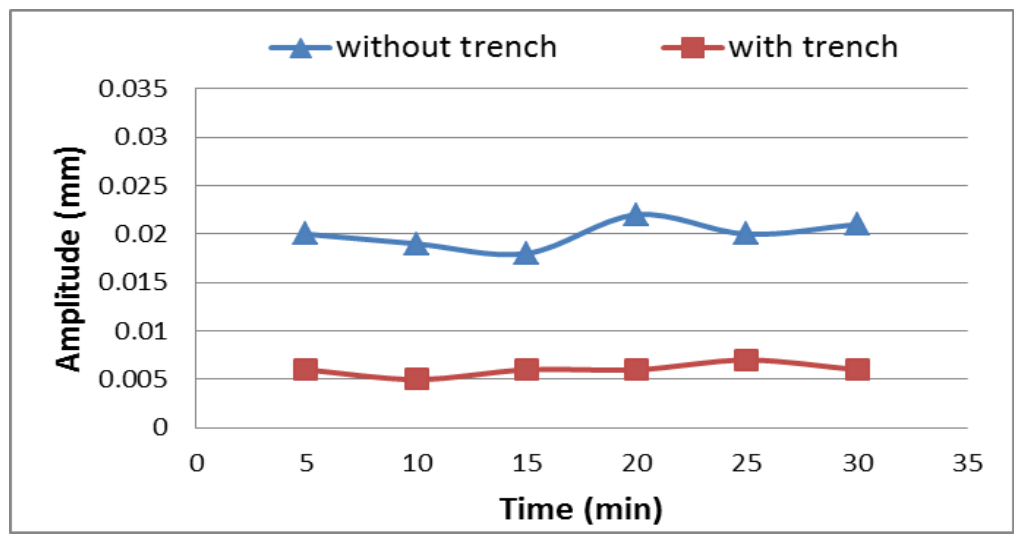

Fig 7. Variation of amplitude with time at frequency $(8 \mathrm{~Hz})$ for $($ length $=3 \mathrm{~B}$, depth $=\mathrm{B}$, thickness $=0.5 \mathrm{~B})$ at soaked state to styropor

\subsection{Amplitude for Low Density Polyethylene (LDPE)}

Figure 8 show the relationship between the amplitude with time for frequency, namely, $8 \mathrm{~Hz}$ for dimensions (length $=3 \mathrm{~B}$, depth $=\mathrm{B}$, thickness $=0.5 \mathrm{~B})$ at dry state. From the figure 8 it can be seen two curves for treated and untreated have similar inclination of conduct from start to end of duration for test, and effect of this technique to reduce the vibration as peak to peak in term of amplitude is $67 \%$.

As for the soaked state, the magnitude of amplitude is finding decrease in Figure 9. Where it can be observes in both curves almost constant until a minute 15 and then after that the rate of improvement increases until the end of test. So, the peak-to-peak improvement is $69 \%$.

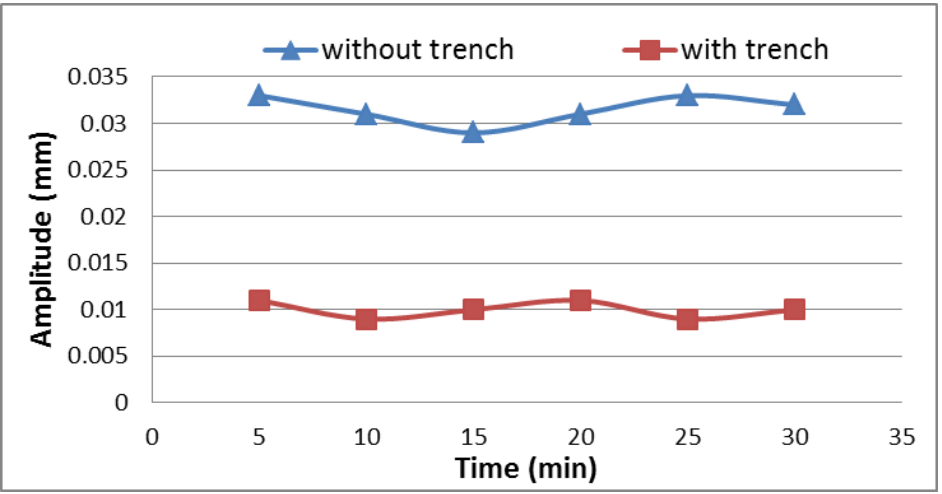

Fig 8. Variation of amplitude with time at frequency $(8 \mathrm{~Hz})$ for $($ length $=3 \mathrm{~B}$, depth $=\mathrm{B}$, thickness $=0.5 \mathrm{~B})$ at dry state to low density polyethylene 


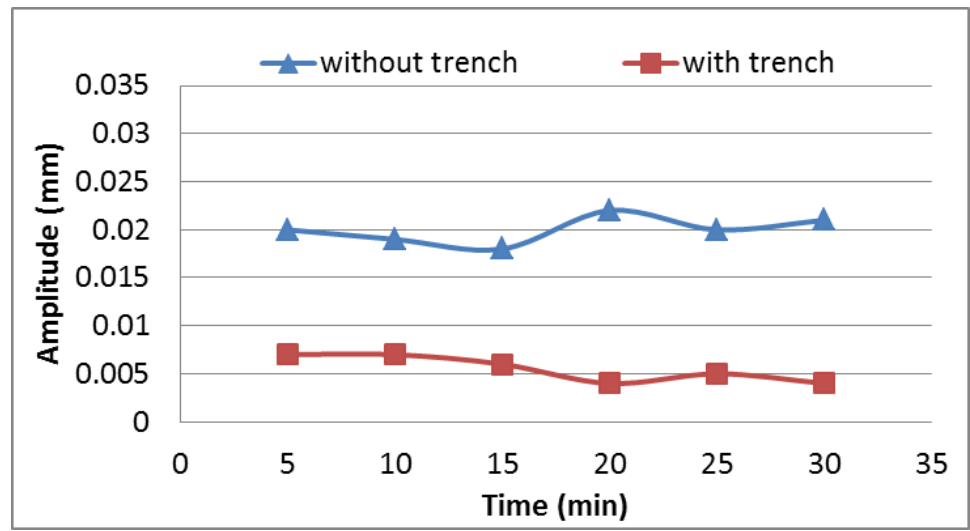

Fig 9. Variation of amplitude with time at frequency $(8 \mathrm{~Hz})$ for (length $=3 \mathrm{~B}$, depth $=\mathrm{B}$, thickness $=0.5 \mathrm{~B})$ at soaked state to low density polyethylene

\subsection{Results of Acceleration}

\subsubsection{Acceleration for Rubber}

Figure 10 shows the relationship between the acceleration with time in frequency, namely $8 \mathrm{~Hz}$ for dimensions of trench (length $=3 \mathrm{~B}$, depth $=\mathrm{B}$, thickness $=0.5 \mathrm{~B}$ ) at dry state. Here, it can observe the rate of improvement in acceleration before and after the vibration isolation in rubber trench, where the trench filled with rubber dampened the effect of vibrations approximately completely. From figure 10 it can be seen the curve of treated is stable (almost) near zero, as for curve of untreated, it can be seen that is little fluctuated, also it has maximum value at minute (5) then decrease until minute (20), after that it is approximately constant. Effect of this technique to reduce the vibration is $99 \%$ for peak to peak acceleration.

In Figure 11 is the same relationship but in soaked state. From the Figure16 it can be observed the curve of untreated has two peaks at minutes $(15,30)$, and it becomes close to a curve treated in the remainder of the test time. From same figure 10 the curve of treated has minimum value vary close to zero (as mentioned earlier). Effect of this technique as percentage of reduction is approximately (99\%) for peak to peak acceleration for treated and untreated.

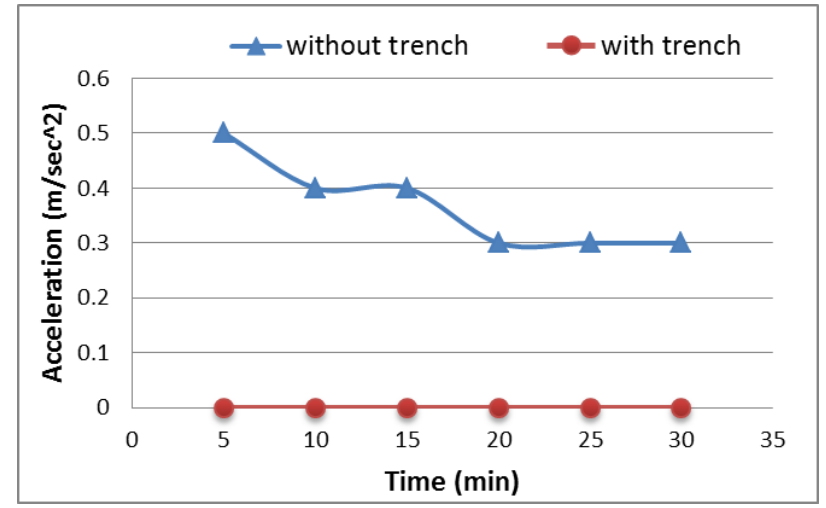

Fig 10. Variation of acceleration with time at frequency $(8 \mathrm{~Hz})$ for $($ length $=3 \mathrm{~B}$, depth=B, thickness $=0.5 \mathrm{~B})$ at dry state to rubber 


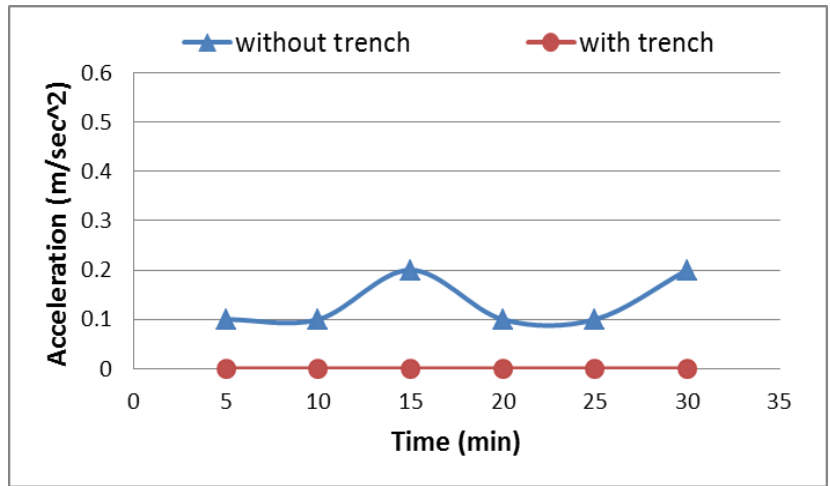

Fig11. Variation of acceleration with time at frequency $(8 \mathrm{~Hz})$ for $($ length $=3 \mathrm{~B}$, depth $=\mathrm{B}$, thickness $=0.5 \mathrm{~B}$ ) at soaked state to rubber

\subsubsection{Acceleration for styropor or rigid foam}

Figure 12 shows the relationship between the acceleration with time in frequency, namely $(8 \mathrm{~Hz})$ for dimensions (length $=3 \mathrm{~B}$, depth=B, thickness $=0.5 \mathrm{~B}$ ) at dry state. From the figure 12 it can be seen that is little fluctuated in the curve of treated, also it starting increase until minute (15) then decrease to become closely to zero almost then increase from minute (25). Effect of this technique to reduce the vibration is $(99 \%)$ for peak to peak acceleration.

As for soak state to same above relationship, it has similar behavior as Figure 11 and Figure 10, the curve of treated nearly zero or ignore see Figure 13 blow.

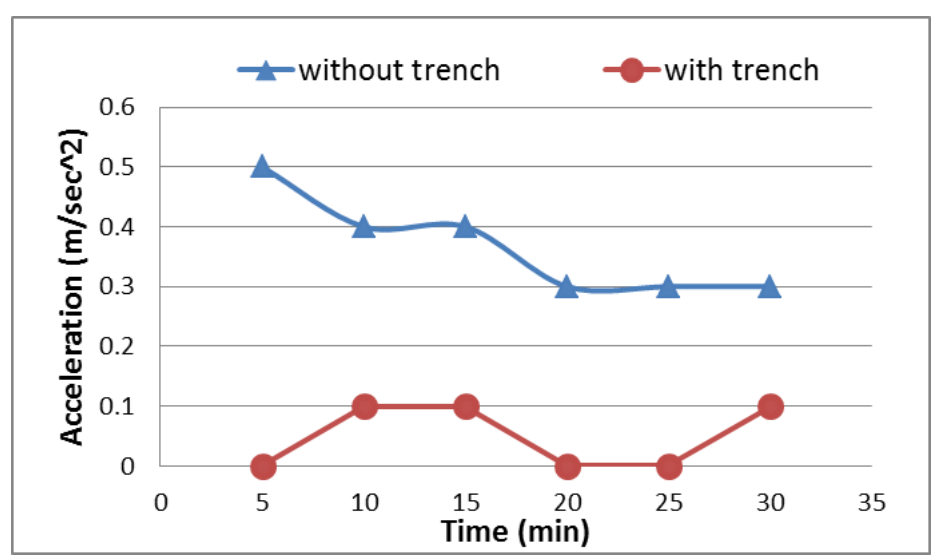

Fig 12. Variation of acceleration with time at frequency $(8 \mathrm{~Hz})$ for $($ length $=3 \mathrm{~B}$, depth=B, thickness $=0.5 \mathrm{~B})$ at dry state to styropor

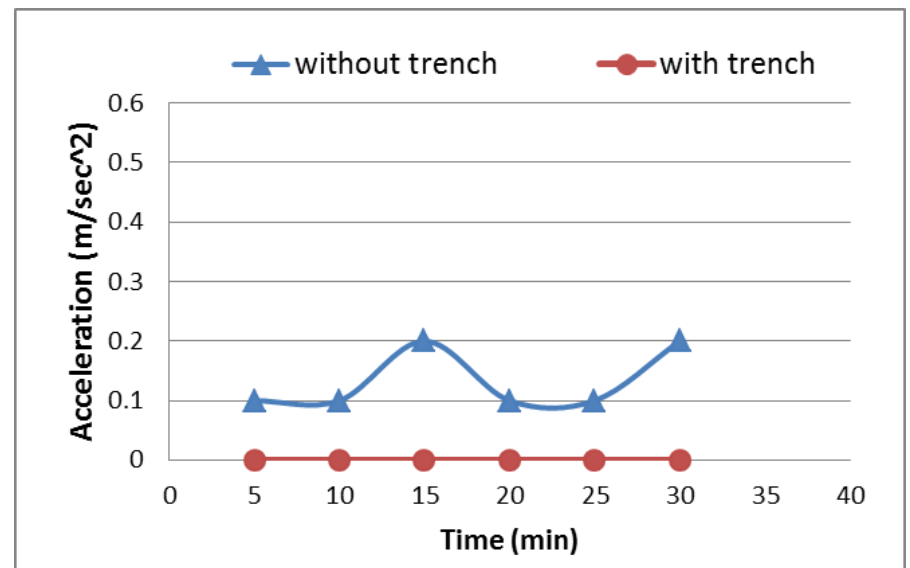

Fig 13. Variation of acceleration with time at frequency $(8 \mathrm{~Hz})$ for $($ length $=3 \mathrm{~B}$, depth $=\mathrm{B}$, thickness $=0.5 \mathrm{~B})$ at soaked state to styropor 
5.3.3 Acceleration for Low Density Polyethylene (LDPE)

Figure 14 show the relationship between the acceleration with time in frequency, namely 8 $\mathrm{Hz}$ for dimensions (length $=3 \mathrm{~B}$, depth $=\mathrm{B}$, thickness $=0.5 \mathrm{~B}$ ) at dry state. From the figure 14 it can be seen that the curve of treated has little fluctuations with constant values near to zero. Effect of this technique to reduce the vibration is $(80 \%)$ for peak to peak in term of acceleration.
Figure 15 the same relationship but in soaked state. From the figure 15 it can be observed the curve of treated is very small approximately equal zero, that mean the effect this technique is clear to mitigate the vibration. Effect of this technique as percentage of reduction is approximately (99\%) for peak to peak acceleration for treated and untreated.

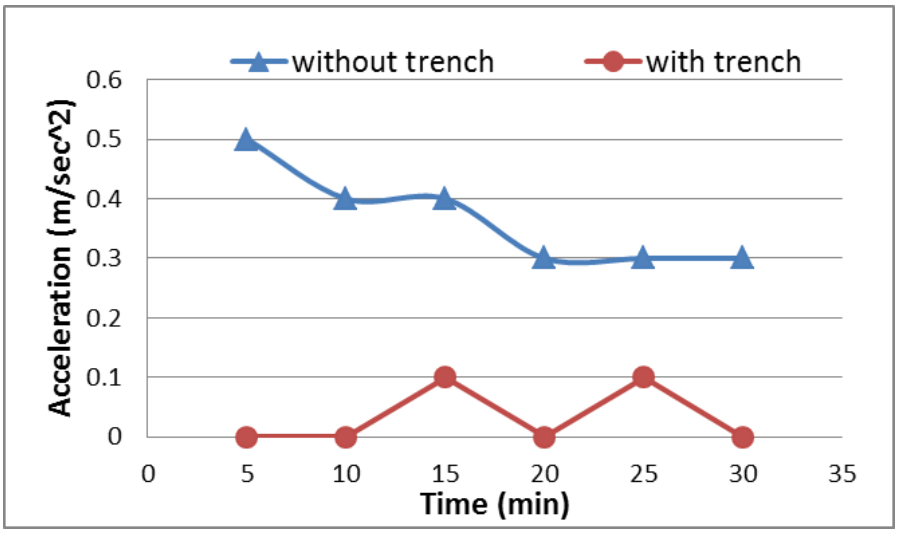

Fig 14. Variation of acceleration with time at frequency $(8 \mathrm{~Hz})$ for $($ length $=3 \mathrm{~B}$, depth $=B$, thickness $=0.5 \mathrm{~B})$ at dry state to low density polyethylene

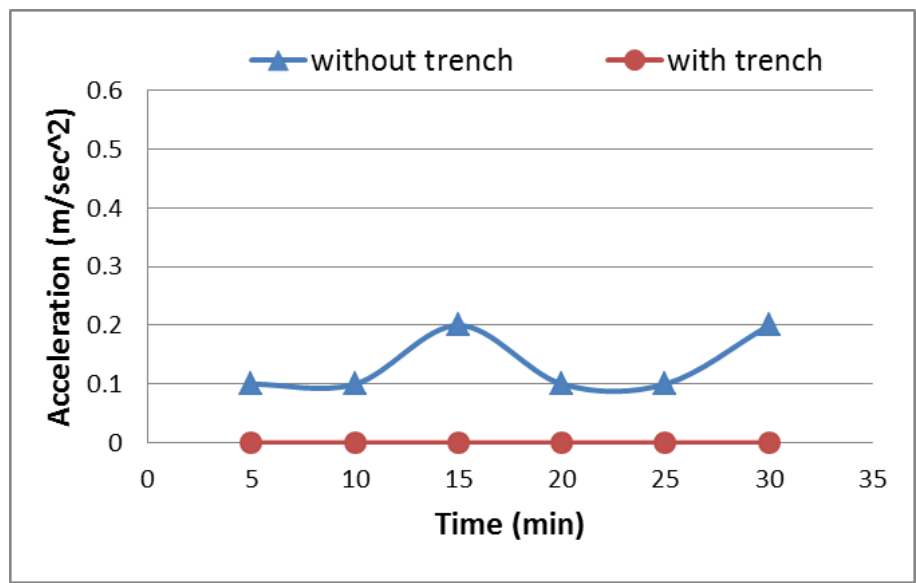

Fig 15. Variation of acceleration with time at frequency $(8 \mathrm{~Hz})$ for $($ length $=3 \mathrm{~B}$, depth $=\mathrm{B}$, thickness $=0.5 \mathrm{~B})$ at soaked state to low density polyethylene

\section{Conclusions}

- The reduction in displacement amplitude for footing when the dimensions of trench (length $=3 \mathrm{~B}$, depth $=\mathrm{B}$, thickness $=0.5 \mathrm{~B}$ ) at frequency of $8 \mathrm{~Hz}$ is $(67 \%, 70 \%$ and $67 \%)$ at dry state in each technique (low density polyethylene, SBR rubber and Styropor) respectively, and $(100 \%, 69 \%, 94 \%$ and $70 \%$ ) at soaking state.

- The acceleration of footing under effect of dynamic load resulting from nearby source decrease with decreasing the operation frequency.

- The reduction in acceleration value for footing when the dimensions of trench (length $=3 \mathrm{~B}$, depth $=\mathrm{B}$, thickness $=0.5 \mathrm{~B}$ ) at frequency of $8 \mathrm{~Hz}$ is $(80 \%, 100 \%$ and $80 \%$ ) at dry state in each technique (low density polyethylene, SBR rubber and Styropor) respectively, and $(100 \%, 100 \%$, $100 \%$ and $100 \%)$ at soaking state. 


\section{References}

[1] Israa Saleh Hussein, Study the effect of fuel oil liquid on engineering properties of gypseous soil, DIYALA JOURNAL OF ENGINEERING SCIENCES, (2017), 60-74.

[2] Safa Hussain Abid Awn "Improvement of gypseous soil by pre-wetting" DIYALA JOURNAL OF ENGINEERING SCIENCES,( 2011),Volume: 4 Issue: 1 Pages: 71-82

[3] Prakash, S. "Soil Dynamics, McGraw-Hill, Inc., New York, 1981.

[4] Dudley, J. H. "Review of Collapsing Soil", Journal of Soil Mechanics and Foundation Engineering, ASCE, Vol. 96, No. 3, 1970, 925-947.

[5] Clemence, P. S. and Finbarr, A. O. "Design Considerations for Collapsing Soils", Journal of the Geotechnical Engineering Division, ASCE, Vol. 107, No.GT3, 1981, 305-317.

[6] Das, B.M., , "Principles of Geotechnical Engineering”, PWS-KENT Publishing Company, Boston, 1990.

[7] Woods RD. " Screening of Surface Waves in soil", Journal of Soil Mechanics and Foundation Engineering ,1968, (ASCE) 1968;94(SM4):95179.

[8] S. Ahmad, T. M. Al-Hussain., "Simplified Design for Vibration Screening by Open and In-Fill Trenches ", Journal of Geotechnical Engineering, Vol. 117, No. 1, 1991, No. 25416.

[9] K. R. Massarsch. "Mitigation of Traffic-induced Ground Vibrations" .Soil Dynamics and Earthquake Engineering and 3rd on Earthquake Geotechnical Engineering, Berkeley,2004. https://www.researchgate.net/publication/2944181 27

[10] Pubudu Jayawardana, Subashi de silva. "Effectiveness of a Trench Filled with Waste Material in Reducing the Propagation of Ground Vibration Induced by Soil Roller Compaction", Engineer - Journal of the Institution of Engineers, Srilanka, 2016, pp. [17-24].

[11] Bosscher, P. J., Edil, T. B. \& Kuraoka, S. "Design of Highway Embankments Using Tire Chips". J. Geo tech. Geoenviron. Engng123, 1997, No. 4, 295-304.

[12] Zornberg, J. G., Cabral, A. R. \& Viratjandr, C. "Behavior of Tire Shred Sand Mixtures". Can. Geo tech. J.41, 2004, No. 2, 227-241.

[13] Senetakis, K., Anastasiadis, A., Trevlopoulos K. \& Pitilakis, K."Dynamic Response of SDOF Systems on Soil Replaced with Sand/Rubber Mixture". Proceedings of COMPDYN ECCOMAS thematic conference on computational methods in structural dynamics and earthquake engineering, Rhodes, Greece, ,2009, pp. 22-24.

[14] B. Sayil and E. GÜrdal. " The Physical Properties of Polystyrene Aggregated Gypsum Blocks" National Research Council Canada, 1999, pp. 496-504.

[15] Ikuo Nakaya, "In-Site and Model Experiments About Ground Vibration Isolation Method by Using Scrap Tire", International Conference on Case Histories in Geotechnical Engineering, 2008, 7, No.4.0.

[16] Hing- Ho Tsang. "Seismic isolation by rubber-soil mixtures for developing countries" Wiley \& Sons, Ltd. ,2007,doi.org/10.1002 /eqe.756. 